\title{
Interleukin-10: A Potential Prognostic Marker in Patients with Newly Diagnosed Multiple Myeloma
}

\author{
Doaa A. Mohammed 1, Salah M. Khallaf ${ }^{2}$, Mohamed G. M. El-Naggar 1, Muhamad R. \\ Abdel-Hameed ${ }^{3}$, Rania Bakry ${ }^{1}$
}

\begin{abstract}
${ }^{1}$ Clinical Pathology Department, South Egypt Cancer Institute, Assiut University, Assiut, Egypt; ${ }^{2}$ Medical Oncology Department, South Egypt Cancer Institute, Assiut University, Assiut, Egypt; ${ }^{3}$ Clinical Hematology Unit, Internal Medicine Department Faculty of Medicine, Assiut University, Assiut, Egypt
\end{abstract}

\begin{abstract}
Background: Identification of high-risk patients with multiple myeloma (MM) is important for improving treatment outcomes. Efforts to identify significant prognostic markers are unremitting. Angiogenesis plays an important mechanism in the progression of MM. One of the mediators of this angiogenic process is interleukin-10 (IL-10).

Aim: To assess the role of IL-10 as a prognostic marker in MM.

Methods: This was a cross-sectional study that included 39 newly diagnosed patients with MM. Serum IL-10 level was measured using Magnetic Luminex ${ }^{\circledR}$ Assay multiplex. The relationship between IL-10 and tumor stage and other known prognostic markers in MM was studied.

Results: The median (interquartile range) value of IL-10 was $3(2.9$ - 3.2) pg/mL. Interleukin-10 level differed significantly according to the revised International Staging System stage of MM, being higher in higher stages. The median (interquartile range) IL-10 level was $2.89(2.79-2.95) \mathrm{pg} / \mathrm{mL}$ in stage I, $3(2.9-3.1)$ in stage II and 3.2 (3.1 $3.66)$ in stage III $(p=0.0009)$. In addition, higher IL-10 significantly correlated with lower hemoglobin $(p=0.002)$, lower albumin $(p=0.045)$, higher creatinine $(p=0.009)$, higher $\beta 2$-microglobulin $(p=0.002)$, higher lactate dehydrogenase $(p=0.0007)$ and higher bone marrow plasma cell percentage $(p=0.015)$.

Conclusion: The results support a prognostic role of IL-10 in MM and its pathogenesis.
\end{abstract}

Keywords: Cytokines, Interleukin-10, Multiple myeloma, Prognosis., Tumor burden.

Corresponding author: Salah Khallaf, MD; Department of Medical Oncology, South Egypt Cancer Institute, Assiut University, Assiut, Egypt; Email: salahmab76@aun.edu.eg

Submitted: 29-November-2020, Finally-revised: 13-January-2021, Accepted: 9-February-2021, Published online: 29-March-2021

\section{Introduction}

Multiple myeloma (MM) is a neoplasm of clonal plasma cells that originate from the post-germinal lymphoid B-cell lineage ${ }^{1}$. It is the second most frequent hematological malignancy after lymphoma and remains largely incurable disease.

Multiple bone marrow microenvironmental changes are involved in the development and progression of MM, as the support provided by the immune microenvironment changes to myeloma cells is crucial for their survival ${ }^{2-4}$.

Interleukin-10 (IL-10) is an immune-regulatory cytokine produced by many cells including macrophages, T-lymphocytes, and natural killer cells. Its role in cancer development is still controversial. It may promote tumor cell proliferation and metastasis via its immunosuppression functions ${ }^{5}$. Its anti-tumour effect may be due to the stimulation of natural killer and cytotoxic T-lymphocytes mediated killing of cancer cells ${ }^{6}$. Research is still required to evaluate the role of IL-10 in the tumorigenesis of MM. In addition, the prognostic role of IL-10 in MM has been suggested. A high level of IL-10 was found to correlate significantly with higher MM stage and $\beta 2$ microglobulin level ${ }^{7}$.

Our aim was to study the relationship between IL10 level and other prognostic markers in MM. 


\section{Methods}

This study was an observational cross-sectional study. It included 39 patients with newly diagnosed MM who presented to the Medical Oncology Department - South Egypt Cancer Institute and the Clinical Hematology Unit - Internal Medicine Department, Assiut University from July 2017 to July 2020.

All patients were proven to have MM according to the International Myeloma Working Group Criteria for the diagnosis of MM and Related Plasma Cell Disorders ${ }^{8}$.

All patients were diagnosed and evaluated at the outpatient clinic of the concerned department. They were subjected to full history taking, clinical examination and laboratory investigations. The laboratory investigations included complete blood picture (using Cell-Dyn Ruby, Abbott Diagnostics, USA), serum chemistry (creatinine, calcium, albumin, lactate dehydrogenase and $\beta 2$ microglobulin, using COBAS Integra 400 Plus, Roche, Switzerland), serum protein electrophoresis and immunofixation (using Pretty Interlab, Interlab, Italy) as well as bone marrow aspiration and trephine biopsies. Interphase fluorescence in situ hybridization (FISH) was performed to stratify the risk of the disease. The disease was staged according to the revised International Staging System (R-ISS).

Serum samples were collected from patients before starting anti-myeloma therapy using a serum separator tube and stored at $-20{ }^{\circ} \mathrm{C}$ for further evaluation. Serum concentration of IL-10 was evaluated according to the manufacturer's instructions using Magnetic Luminex ${ }^{\circledR}$ Assay multiplex kits (Human Premixed Multi-Analyte Kit, R\&D Systems, Bio-Techne, Minneapolis, USA).

\section{Statistical analysis}

Continuous data were presented as mean and standard deviation (SD) or median and range, while categorical data as frequency and percentage. For abnormally-distributed quantitative data, comparison between two groups was done using Mann-Whitney and between more than two groups by Kruskall Wallis test. Correlations were assessed using the Spearman's rank correlation coefficient.

Data analysis was done using the IBM Statistical Package for Social Science (SPSS) for Windows, Version 21.0. (Armonk, NY: IBM Corp).

\section{Ethical considerations}

The study was approved by the Institutional Review Board of the South Egypt Cancer Institute, Assiut University (approval No: 380).

An informed written consent was taken from all patients and controls.

\section{Results}

The demographic and clinical characteristics of patients are summarized in Table 1 . Two-thirds were males and their mean age was $58( \pm 8.8)$ years.

Table 1: Demographic and clinical characteristics of 39 patients with multiple myeloma

\begin{tabular}{|c|c|c|}
\hline \multirow{2}{*}{$\begin{array}{l}\text { Variable } \\
\text { Age (years) }\end{array}$} & \multicolumn{2}{|l|}{ Description } \\
\hline & Mean (SD) & $58.3(8.8)$ \\
\hline \multicolumn{3}{|l|}{ Sex } \\
\hline Male & $n(\%)$ & $29(74.4)$ \\
\hline Female & $n(\%)$ & $10(25.6)$ \\
\hline \multicolumn{3}{|l|}{ R-ISS stage } \\
\hline I & $n(\%)$ & $8(20.5)$ \\
\hline II & $n(\%)$ & $17(43.5)$ \\
\hline III & $n(\%)$ & $14(36)$ \\
\hline $\begin{array}{l}\text { Bone marrow plasma } \\
\text { cells }(\%)\end{array}$ & Median (IQR) & $30(10-90)$ \\
\hline \multicolumn{3}{|l|}{ Monoclonal protein type } \\
\hline $\operatorname{IgG}$ & $n(\%)$ & $38(97.4)$ \\
\hline IgA & $n(\%)$ & $1(2.6)$ \\
\hline \multicolumn{3}{|l|}{ Light chain type } \\
\hline Lambda & $n(\%)$ & $30(76.9)$ \\
\hline Kappa & $n(\%)$ & $9(23.1)$ \\
\hline \multicolumn{3}{|l|}{ Osteolytic lesion } \\
\hline Yes & $n(\%)$ & $35(89.7)$ \\
\hline No & $n(\%)$ & $4(10.3)$ \\
\hline Calcium (mg/dL) & Mean (SD) & $10.1(1.3)$ \\
\hline Hemoglobin (g/dL) & Mean (SD) & $9.9(2.5)$ \\
\hline Albumin (gm/dL) & Median (IQR) & $\begin{array}{l}33.2 \quad(16- \\
45)\end{array}$ \\
\hline Creatinine (mg/dL) & Median (IQR) & $1(0.3-12)$. \\
\hline $\begin{array}{l}\begin{array}{l}\text { Lactate dehydrogenase } \\
(\mathrm{U} / \mathrm{L})\end{array} \\
\end{array}$ & Median (IQR) & $\begin{array}{l}350 \quad(105- \\
777)\end{array}$ \\
\hline B2-microglobulin (mg/l) & Median (IQR) & $5(1.2-15.6)$ \\
\hline IL10 (pg/mL) & Median (IQR) & $3(2.9-3.2)$ \\
\hline
\end{tabular}

SD: Standard deviation; IQR: Interquartile range, R-ISS: Revised International Staging System 
The correlation between IL-10 level and the studied variables is detailed in Table 2 .

Table 2: Correlation between interleukin-10 level and the studied variables

\begin{tabular}{|c|c|c|}
\hline \multirow[t]{2}{*}{ Variable } & $\begin{array}{l}\text { Interleukin-10 } \\
(\mathrm{pg} / \mathrm{mL})\end{array}$ & \multirow[t]{2}{*}{$p$ value } \\
\hline & Median (IQR) & \\
\hline \multicolumn{3}{|l|}{ Sex } \\
\hline Male & $3(2.9-3.2)$ & \multirow[t]{2}{*}{0.447} \\
\hline Female & $3(2.9-3.1)$ & \\
\hline \multicolumn{3}{|l|}{ R-ISS stage } \\
\hline I & $2.89(2.79-2.95)$ & \multirow[t]{3}{*}{0.0009} \\
\hline II & $3(2.9-3.1)$ & \\
\hline III & $3.2(3.1-3.66)$ & \\
\hline
\end{tabular}

\begin{tabular}{lll}
\hline Light chain type & \\
\cline { 1 - 2 } Lambda & $3.1(2.89-3.2)$ & 0.136 \\
\hline Kappa & $2.9(2.9-3)$ & \\
\hline Osteolytic lesion & & \\
\cline { 1 - 2 } Yes & $3(2.89-3.2)$ & 0.78 \\
No & $3.1(2.95-3.15)$ & \\
\hline
\end{tabular}

\begin{tabular}{|c|c|c|}
\hline \multicolumn{3}{|c|}{ Calcium (mg/dL) } \\
\hline$\leq 12$ & $3(2.89-3.2)$ & \multirow[t]{2}{*}{0.198} \\
\hline$>12$ & $3.2(2.9-48.37)$ & \\
\hline \multicolumn{3}{|c|}{ Hemoglobin (g/dL) } \\
\hline$>10$ & $2.95(2.88-3)$ & \multirow[t]{3}{*}{0.002} \\
\hline $8.5-10$ & $3.05(2.95-3.25)$ & \\
\hline$<8.5$ & $3.2(3.08-5.84)$ & \\
\hline
\end{tabular}

\begin{tabular}{|c|c|c|}
\hline Albumin (gm/dL) & & \\
\hline$\geq 3.5$ & $2.99(2.88-3.08)$ & 0.0449 \\
\hline$<3.5$ & $3.11(2.95-3.3)$ & \\
\hline \multicolumn{3}{|l|}{ Creatinine (mg/dL) } \\
\hline$<2$ & $3(2.88-3.1)$ & 0.009 \\
\hline$\geq 2$ & $3.2(3.03-3.6)$ & \\
\hline
\end{tabular}

\begin{tabular}{ll}
\hline $\boldsymbol{\beta 2}$-microglobulin $(\mathrm{mg} / \mathrm{l})$ & \\
\hline$<3.5$ & $2.9(2.86-3.03)$ \\
\hline $3.5-<5.5$ & $3(2.89-3.06)$ \\
\hline$\geq 5.5$ & $3.2(3.1-3.66)$
\end{tabular}

\begin{tabular}{lll}
\hline & Spearman's rho & $p$ value \\
\cline { 2 - 3 } Age (years) & 0.1 & 0.544 \\
\hline $\begin{array}{l}\text { Lactate dehydrogenase } \\
\text { (U/L) }\end{array}$ & 0.522 & 0.0007 \\
\hline $\begin{array}{l}\text { Bone marrow plasma } \\
\text { cells (\%) }\end{array}$ & 0.387 & 0.015 \\
\hline
\end{tabular}

IQR: Interquartile range, R-ISS: Revised International Staging System

The following variables significantly correlated with higher IL-10 level: higher R-ISS stage, lower hemoglobin level, lower albumin level, higher creatinine level, higher $\beta 2$-microglobulin level, higher lactate dehydrogenase level, and higher percentage of plasma cells in the bone marrow. Although IL-10 level was higher in patients with osteolytic lesions and a calcium level above 12 $\mathrm{mg} / \mathrm{dL}$, this was not statistically significant.

\section{Discussion}

The interaction of plasma cells with bone marrow microenvironment mediates myeloma disease progression ${ }^{9}$. Multiple myeloma remains largely an incurable disease despite the development of many therapeutic agents, such as bortezomib and lenalidomide. Failure to cure is multifactorial and can be attributed to the underlying genetic aberrations and to the surrounding microenvironment ${ }^{10}$.

Accurate identification of high-risk patients and risk stratification are very important in improving outcomes of MM patients. A large number of prognostic markers have been described, but none of them completely explains the heterogeneity seen in this tumor ${ }^{11}$.

Interleukin-10 is an anti-inflammatory cytokine that plays a crucial role in the immune suppressive microenvironment in $\mathrm{MM}^{12}$. It is involved in the terminal differentiation of B-cells into plasma cells and enhances its proliferation. Furthermore, it seems to enhance the proliferation of MM cells ${ }^{13}$.

Previous studies showed that IL-10 level is higher in patients with MM when compared with controls without MM ${ }^{12,14,15}$. Wang et al ${ }^{12}$ found that IL-10 serum concentration in their studied MM patients was much higher than in normal controls. Also, Alexandrakis et al ${ }^{14}$ reported that serum level of IL10 was significantly higher in newly diagnosed MM patients compared to healthy controls and its level was significantly related to high ISS stage. A similar finding was reported by Aref et al ${ }^{15}$.

Our study showed a significantly higher serum levels of IL-10 in MM patients with advanced ISS stages and this falls in line with previous studies ${ }^{14}$.

In addition to the strong association between IL10 level and stage found in this study, IL-10 level positively correlated with other individual prognostic markers of MM, such as serum $\beta 2$ microglobulin and bone marrow plasma cells percentage. This is in agreement with Shekarriz et al ${ }^{11}$ who demonstrated that there was a significant correlation between elevated IL-10 levels and serum $\beta 2$-microglobulin concentration and a trend for a positive correlation between the IL-10 level and 
bone marrow plasma cells percentage. Wang et al ${ }^{12}$ also found that the serum level of IL-10 was significantly higher in patients with higher bone marrow plasma cells percentage, as well as those with elevated serum $\beta 2$-microglobulin and lactate dehydrogenase levels. Similarly, Gu et al ${ }^{16}$ reported that serum IL-10 level showed significant positive correlations with lactate dehydrogenase and serum $\beta 2$-microglobulin concentrations. This further confirms the possible prognostic role of IL-10 in MM.

In addition to IL-10, the prognostic role of other cytokines, like IL-6 and IL-17A, in MM has been recently suggested ${ }^{16}$. More research is needed to confirm the prognostic value of IL-10 and other cytokines and to study the value of incorporating them into the current staging systems.

\section{Conclusion}

The results of this study confirm the association between higher IL-10 level and advanced stage and other prognostic markers in patients with MM. The incorporation of IL-10 in risk stratification of MM may be considered. Further studies with larger sample and outcome evaluation are needed to validate its prognostic role.

\section{Acknowledgment \\ None. \\ Authors' contribution \\ Conception or design: DAM, SMK, RB; Acquisition, analysis or interpretation of data: DAM, SMK, MGME, RB; Drafting the manuscript: DAM, SMK, MRA, RB; Revising the manuscript: MGME; Approval of the manuscript version to be published: All authors; Agreement to be accountable for all aspects of the work: All authors. \\ Conflict of interest \\ The authors declare that they have no conflict of interest to disclose.}

\section{Data availability}

Deidentified individual participant data used to produce the results of this study are available from the corresponding author (SMK) upon request.

\section{Funding}

The authors did not receive funding for this study.

\section{Study registration}

None.

\section{References}

1. Kazandjian D, Mailankody S, Korde N, Landgren O. Smoldering multiple myeloma: pathophysiologic insights, novel diagnostics, clinical risk models, and treatment strategies. Clin Adv Hematol Oncol. 2014; 12(9): 578-587.
2. Frenquelli M, Caridi N, Antonini E, et al. The WNT receptor ROR2 drives the interaction of multiple myeloma cells with the microenvironment through AKT activation. Leukemia. 2020; 34(1): 257-270.

3. Lopes R, Caetano J, Ferreira B, Barahona F, Carneiro EA, João C. The immune microenvironment in multiple myeloma: Friend or foe? Cancers (Basel). 2021; 13(4): 625.

4. Moser-Katz T, Joseph NS, Dhodapkar MV, Lee KP, Boise LH. Game of bones: How myeloma manipulates its microenvironment. Front Oncol. 2021; 10: 625199.

5. Sheikhpour E, Noorbakhsh P, Foroughi E, Farahnak $\mathrm{S}$, Nasiri R, Neamatzadeh H. A survey on the role of interleukin-10 in breast cancer: A narrative. Rep Biochem Mol Biol. 2018; 7(1): 30-37.

6. Mannino MH, Zhu Z, Xiao H, Bai Q, Wakefield MR, Fang Y. The paradoxical role of IL-10 in immunity and cancer. Cancer Lett. 2015; 367(2): 103-107.

7. Shekarriz R, Janbabaei G, Abedian Kenari S. Prognostic value of IL-10 and its relationship with disease stage in Iranian patients with multiple myeloma. Asian Pac J Cancer Prev. 2018; 19(1): 27-32.

8. Rajkumar SV, Dimopoulos MA, Palumbo A, et al. International Myeloma Working Group updated criteria for the diagnosis of multiple myeloma. Lancet Oncol. 2014; 15(12): e538-548.

9. Noonan K, Borrello I. The immune microenvironment of myeloma. Cancer Microenviron. 2011; 4(3): 313-323.

10. Mondello P, Cuzzocrea S, Navarra M, Mian M. Bone marrow micro-environment is a crucial player for myelomagenesis and disease progression. Oncotarget. 2017; 8(12): 20394-20409.

11. Saltarella I, Morabito F, Giuliani N, et al. Prognostic or predictive value of circulating cytokines and angiogenic factors for initial treatment of multiple myeloma in the GIMEMA MM0305 randomized controlled trial. J Hematol Oncol. 2019; 12(1): 4.

12. Wang H, Wang L, Chi P-D, et al. High level of interleukin-10 in serum predicts poor prognosis in multiple myeloma. Br J Cancer. 2016; 114(4): 463-468.

13. Kovacs E. Interleukin-6 leads to interleukin-10 production in several human multiple myeloma cell lines. Does interleukin-10 enhance the proliferation of these cells? Leuk Res. 2010; 34(7): 912-916.

14. Alexandrakis MG, Goulidaki N, Pappa CA, et al. Interleukin-10 induces both plasma cell proliferation and angiogenesis in multiple myeloma. Pathol Oncol Res. 2015; 21(4): 929-934.

15. Aref S, Azmy E, El-Gilany AH. Upregulation of CD200 is associated with regulatory $\mathrm{T}$ cell expansion and disease progression in multiple myeloma. Hematol Oncol. 2017; 35(1): 51-57.

16. Gu J, Huang X, Zhang Y, Bao C, Zhou Z, Jin J. Cytokine profiles in patients with newly diagnosed multiple myeloma: Survival is associated with IL-6 and IL-17A levels. Cytokine. 2021; 138: 155358. 